\title{
ASSESSMENT OF KNEE OSTEOARTHRITIS USING THERMOGRAPHY
}

\author{
Subitcha Jayashankar¹, Deepika.M², Verinder Pal Singh Bali, Manickavallini.P*1, \\ Dr.N.S.Rajarajan ${ }^{\# 1}$
}

$1,2,3$

IV year Students,Department of Biomedical Engineering, SRM University, Kattankulathur-603203, Tamil Nadu, India .

${ }^{* 1}$ Faculty of Department of Biomedical Engineering, SRM University, Kattankulathur-603203,

${ }^{\# 1}$ Public Health Centre- lake view road, West Mambalam, Chennai- 600033.

Email:1 subijayasankar@gmail.com, ${ }^{2}$ mdeepika2408@gmail.com, ${ }^{3}$ verinderpal.singh@gmail.com, ${ }^{* 1}$ vallinidg@gmail.com, \#1drnsrajarajan@yahoo.com.

\begin{abstract}
Osteoarthritis (OA) is a degenerative disease which affects the cartilage, joint lining, ligaments and bone. Although X ray is the gold standard method, thermal imaging technique is a novel imaging technique that is used for diagnosing OA. Digital infrared thermal imaging is a means of measuring heat radiated from skin surface. The objective of the study is 1) To analyze the temperature in knee OA subjects and to compare with the normal subjects using thermal imaging. 2) To segment the image using $\mathrm{K}$ means clustering algorithm and Robert's edge detection algorithm using MATLAB. On the thermal images obtained, temperatures of knee regions were analyzed. Basic statistical analysis (minimum, maximum, standard deviation, mean and span) were performed. There is statistically a significant difference in knee temperature for OA and normal subjects. Thus using thermography, the OA subjects and the normal subjects can be differentiated. K means segmentation algorithm gives better result of segmentation. Mean value of the skin surface temperature of the knee at anterio-posterior position observed in healthy subjects was in the range from $31.3^{\circ} \mathrm{C}$ to $34.7^{\circ} \mathrm{C}$ and in the patients who suffered from osteoarthritis was from $32^{\circ} \mathrm{C}$ to $36.3^{\circ} \mathrm{C}$
\end{abstract}

Keywords-Osteoarthritis, Thermography, Thermal imaging, K-means clustering algorithm, Robert's edge detection algorithm 